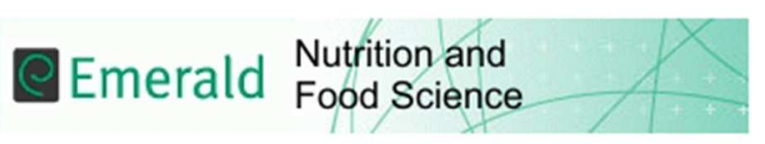

The effect of shift work on the diet of accident and emergency nurses at a general hospital in Malta

\begin{tabular}{|r|l|}
\hline Journal: & Nutrition and Food Science \\
\hline Manuscript ID & NFS-05-2016-0059.R2 \\
\hline Manuscript Type: & Original Article \\
\hline Keywords: & Dietary Intake, Shift work, obesity, Nurses \\
\hline \multicolumn{2}{|c}{} \\
\\
\multicolumn{3}{|c}{$\begin{array}{r}\text { SCHOLARONE } \\
\text { Manuscripts }\end{array}$} \\
\end{tabular}




\title{
The effect of shift work on the diet of accident and emergency nurses in a general hospital in Malta
}

\begin{abstract}
Purpose - The purpose of this paper was to investigate the effect of shift work on diet and lifestyle in nurses working in the accident and emergency department in a general hospital in Malta.

Design/methodology/approach - This study was a cross-sectional, quantitative survey whereby data were collected by the use of anonymous questionnaires consisting of a demographic and anthropometric questionnaire, a lifestyle questionnaire and a food frequency questionnaire to assess dietary intakes. 110 nurses completed the study and were divided into 3 groups; day nurses, rotating shift nurses and night shift nurses.
\end{abstract}

Findings - Shift working nurses consumed significantly more energy compared to day nurses (night shift nurses $1963 \pm 506 \mathrm{kcal}$; rotating shift nurses $2065 \pm 655 \mathrm{kcal}$; day nurses $1722 \pm$ $486 \mathrm{kcal}) ;(p=0.04)$. Shift working nurses also consumed more protein $(p=0.04)$, fat $(p=$ $0.047)$ and fibre $(p=0.005)$ compared to day nurses, however day nurses were the most likely to smoke $(p=0.009)$.

Practical implications Shift work does influence the diet of nurses in Malta. It is recommended that access to healthy food and time and facilities for physical activity are made available across all working hours and that nurses aim to exercise regularly, eat healthily, quit smoking if necessary and get good quality sleep where possible.

Originality/value $-22 \%$ of workers in Malta work shifts, and Malta currently has one of the highest rates of obesity in Europe. This study considers the impact of shiftwork on diet. 
Keywords - diet, nurses, obesity, shift work

Paper type - Research paper

\section{Introduction}

In Malta, 22.2\% of workers are engaged in shift work (Formosa, 2009) and this figure appears to be on the increase. Across Europe generally $21 \%$ of workers are required to work shifts and this has increased by 4\% since in 2005 (Eurofound, 2015). One third of people in the health care sector are required to work shifts (Eurofound, 2005) since most hospitals and nursing homes operate essential services 24 hours a day.

Shift work is known to affect sleeping patterns, eating behaviour and can result in altered levels of physical activity (Persson \& Martensson, 2006) that may disrupt the natural circadian rhythm (Lowden et al., 2010;) and potentially lead to symptoms such as gastrointestinal disorders (Nojkov et al., 2010; Knutsson \& Bogglid, 2000), high blood pressure and mood disorders (Driesen et al., 2010). Some studies have shown that there is a greater incidence of obesity amongst shift workers (Macagnan et al., 2012; Li et al., 2011) and that shift work may be associated with higher risk of insulin resistance, diabetes, dyslipidemias and metabolic syndrome (Zimberg et al., 2012) and even possibly increased incidence of cancer (Lieu et al., 2012).

Malta has been identified as a country with one of the highest rates of overweight and obesity in Europe. In 2015 68.5\% of men and 59.6\% of women were classified as being overweight (World Health Organisation (WHO), 2015) and since there appears to be a greater incidence of obesity amongst shift workers, it is clear that a healthy lifestyle including diet is of the upmost importance for workers who regularly work shifts. 
In light of the high rates of overweight and obesity in Malta and the high incidence of shiftwork amongst healthcare workers, this study aimed to investigate the dietary intake and lifestyle of nurses that work shifts in the Accident and Emergency (A\&E) Department at the main general hospital in Malta. The A\&E department was chosen in particular because unlike other departments in the hospital there is an equal distribution of nurses on all shifts throughout the 24 hours of the day.

\section{Materials Methods}

\section{Study Design and Participants}

The study was a cross-sectional, quantitative survey whereby data were collected by the use of anonymous questionnaires. The participants were all nurses working in the Accident and Emergency (A\&E) Department in a general hospital on the island of Malta. Data were collected from January until February 2015.

146 nurses over the age of 18 years were initially recruited, 123 nurses completed the questionnaire, 13 were excluded on the grounds of incompletion (5), new to the job (4), pregnancy (1) and illness (3). In total 110 nurses completed the study. The participants were divided into 3 groups according to their usual work rota: day nurses $(n=29,31 \%$ male and $69 \%$ female), rotating shift nurses $(n=68,28 \%$ male and $72 \%$ female) and night shift nurses $(\mathrm{n}=13,23 \%$ male and $77 \%$ female). The usual working shift was a 12 hour shift starting at 7:00hrs for the day shift and 19:00 hrs for the night shift. The rotating shift roster is typically spread over four days which includes a day shift, a night shift, followed by a rest and a day off.

Data Collection 
Questionnaires were used to ascertain information about lifestyle and some basic anthropometric measurements. The questionnaires were made available in the Accident and Emergency department. Blank envelopes were distributed with the questionnaires so once completed the questionnaires could be posted anonymously into a locked box.

Dietary intake was assessed using the EPIC-Norfolk Food Frequency Questionnaire (FFQ) (European Prospective Investigation of Cancer, 2015) that was adapted to reflect the Maltese diet e.g. using examples of foods commonly consumed in Malta. The EPIC-Norfolk FFQ was selected because it is relatively quick and easy to complete and included a semiquantitative indication of portion sizes. A specifically designed questionnaire was created to ask details about the demographic and anthropometric measurements of the nurses. To facilitate the anthropometric measurements weighing scales, a stadiometer and a tape measure were made available in the study area in the A\&E department, so weight, height, waist circumference and hip circumference could be reported. Pictorial guides showing how the measurements should be correctly determined were provided to all participants. Body mass index (BMI) was calculated from height and weight according to the formula $\left(\mathrm{kg} / \mathrm{m}^{2}\right)$ and classification issued by the World Health Organisation (2015).

The questionnaire was piloted amongst 10 nurses working in departments other than $A \& E$ at the hospital to ensure clarity of the questions. These results were not included in the final data set.

\section{Ethical approval}

Ethical approval was granted by the University of Roehampton, the University of Malta and the Hospital Authority. All participants provided written consent and were aware they could retire from the study at any time without reason. Participants were assured that their data would be coded anonymously. 


\section{Statistical Analysis}

The dietary information was analysed using Dietplan (Forestfield software, Sussex, UK) to identify the amount of individual nutrients consumed. The data were calculated as mean per day and exported to the IBM SPSS statistics v21 program (SPSS Inc., Chicago, IL, USA3333) for analysis. The categorical variables socio-demographic background, physical exercise and smoking data were compared using the Fisher exact test or Pearsons Chi-Square test. Analysis of variance (ANOVA) and univariate analysis of variance (UNIANOVA) were utilised to investigate differences in anthropometric measurements and dietary intake variables between shift work groups. Confounders included age and gender, since both may influence BMI. Multiple comparisons were tested using the Scheffe (post hoc) test. Data are presented as mean \pm standard deviation. A significance level of $p \leq 0.05$ was adopted.

\section{Results}

Table 1 here

The number of participants, age and anthropometric measurements of the nurses according to gender and shift worked is presented in table 1 . In total $32 \%$ of the nurses were overweight and $19 \%$ were obese. Both male and female nurses that worked rotating shifts were significantly $(p=0.001)$ younger (female nurses $26.7 \pm 5.0$ years; male nurses $26.8 \pm 3.8$ years) than day (female nurses $34.5 \pm 10.0$ years, male nurses $38.7 \pm 15.2$ years) and night nurses (female nurses $41.7 \pm 11.5$ years, male nurses $35.3 \pm 5.0$ years). Age was associated with BMI however there were no differences in BMI between groups (see table 1). For this 
reason UNIANOVA was applied to test for between-subject effects using BMI as a dependent variable by shift type with age. The latter was found to be associated with BMI ( $p$ $=0.03)$ whereas no differences were found between BMI and the three shift patterns $(p=$ 0.26). Night nurses had the highest waist circumferences (female nurses $91.7 \pm 13.5 \mathrm{~cm}$, male nurses $92.2 \pm 12.4 \mathrm{~cm}$ ) compared to day (female nurses $80.2 \pm 11.8 \mathrm{~cm}$, male nurses $87.3 \pm 13.2 \mathrm{~cm}$ ) and rotating shift nurses (female nurses $81.9 \pm 13.4 \mathrm{~cm}$, male nurses $94.6 \pm$ $12.5 \mathrm{~cm})$, although the difference was weak $(p=0.06)$; significance only increased slightly when age was used as a covariate $(p=0.059)$. However male night shift nurses had significantly greater $(p=0.02)$ waist hip ratios $(1.1 \pm 0.1)$ than day $(0.91 \pm 0.006)$ or rotating shift male nurses $(0.93 \pm 0.07)$.

Figure 1 here

In terms of hours at work, all groups reported that they regularly did overtime; however day nurses and rotating shift nurses worked significantly $(p<0.001)$ longer hours than night nurses. Rotating shift nurses generally had the least years of experience in the job but were most likely to have degree level education $(p=0.049)$. In terms of lifestyle habits (Figure 1$)$, there were no significant differences in physical activity levels between groups, however $34 \%$ of the nurses reported not doing any physical activity outside of work. There were no differences in alcohol consumption between groups, of those that did consume alcohol red wine was the most commonly consumed drink. The majority of nurses in this study were non-smokers, however $38 \%$ of day workers were smokers compared to $12 \%$ of rotating shift nurses and $8 \%$ of night nurses. Day nurses were significantly more likely to smoke ( $p=$ 0.009), gender did not exert any effect on this finding. 
Table 2 shows the nutrient intake of nurses as organised by shift pattern, for males and females separately and combined.

Table 2 here

A Scheffe test revealed that nurses that worked night $(1963 \pm 506 \mathrm{kcal})$ or rotating shifts $(2065 \pm 655 \mathrm{kcal})$ consumed significantly more energy, compared to day nurses $(1722 \pm 486$ kcal); $(p=0.04)$. Shift working nurses also consumed more protein, fat and fibre compared to day nurses (Table 2a). Similarly from the female only data (Table 2b) it was revealed that female nurses who worked night or rotating shifts consumed significantly more protein and fibre. Amongst the male nurses (Table 2c) there were no significant differences in the nutrients consumed. There were no significant findings in relation to specific foods consumed but there was tendency for night shift nurses to consume more foods that could be classed as healthy snacks such as fruit, yoghurt and nuts.

\section{Discussion}

Significant trends in the likelihood of shift workers being overweight and at risk of obesity have been reported in a variety of previous studies (Karlsson et al., 2001, Zhao et al., 2011). In this study $51 \%$ of the nurses were overweight or obese $(61 \%$ of male nurses and $49.1 \%$ female nurses were overweight or obese). Despite the day nurses having lower energy intakes compared to the rotating and night shift workers there was no differences in BMI 
between groups, this could possibly be explained by differences in energy expenditure since $48 \%$ of day nurses reported doing no physical activity outside of work. It is also noteworthy that the incidence of overweight and obesity reported amongst the nurses in this study was lower than the $68 \%$ of males and $59.6 \%$ of females in Malta reported by WHO (2015). The difference found between the general Maltese population and the sample population could be described as multifactorial, however the participants in this study were all nurses thus perhaps having a greater knowledge of health and health behaviours than the Maltese population in general. Furthermore, the majority of the nurses in this study were generally young, single, and female. However, the overweight and obesity results in this study were similar to that reported in Californian nurses (Chin et al., 2016) where 49\% of nurses were reported as being overweight or obese but below the results from a Scottish study that described $69 \%$ of nurses as overweight or obese (Kyle et al., 2016). A study (Marqueze et al., 2012) of 446 Brazilian nurses found night workers with higher education level were more likely to gain weight than day nurses and this was particularly marked in older nurses, however this study did not explore nutritional intakes which could influence weight gain. Nurses may be at particularly high risk of being overweight or obese because of the nature of their work which can be stressful as well as affected by limited access to healthy food and facilities for physical activity (Atkinson et al., 2008; Griep et al., 2014). It is acknowledged that the anthropometric measurements in this study were reliant on self-report and this may have affected the accuracy of the results. However Dekkers et al., (2008) described self- reported measures to be valid tools in cross-sectional epidemiological studies and amongst working populations.

The majority of nurses in this study were non-smokers however, more day workers smoked compared to rotating or night shift nurses. Other studies have reported that shift workers are 
more likely to smoke (Reeves, 2004) and both Marqueze et al. (2012) and Griep et al. (2014) reported that night nurses in particular were more likely to smoke a greater number of cigarettes. Smoking may be linked to stress and it has been previously noted that A\&E nurses are particularly vulnerable to stress (Adeb-Saeedi, 2002). Smoking cessation support would be of immediate benefit and many hospitals are now smoke free zones. In this study more day nurses reported not exercising regularly. It is likely that nurses who work long hours want to prioritise their time to be with friends and family when not working (Atkinson et al., 2008). Other studies state that physical activity is less common in shift working nurses, for example Chin et al. (2016) report regular muscle-strengthening physical activity to be significantly less common among nurses working on non-day shifts. Physical activity could help with stress relief and promote better sleep (Chennaoui, 2105) even in those with sleep disorders (Erlacher et al., 2015).

This study showed that nurses who worked night or rotating shifts consumed significantly more energy, protein, fat and fibre than nurses who worked days, however there were no differences in alcohol consumption. The increase in protein fat and fibre are likely a direct result of the increase in energy intake. In terms of total energy intake, other studies have reported that caloric intakes are not always affected by shiftwork (Reeves et al., 2004; Lennernas et al., 1994). Atkinson (2008) reviewed the literature and reported that even where there are no differences in the calorie intakes there may be changes to eating patterns whereby meal frequency is reduced but snacking increases. It has been reported that some shift workers consume alcohol as a sleep aid and a recent study suggested young males were at particular risk (Dorrian et al., 2015) however this was not the case in this study, however differences in gender and age in the sample groups could help explain the dissimilar results. 
Working in A \&E can be demanding with physical and psychological pressures and this may at times affect food intakes and contribute to meal skipping and snacking (Dallman et al., 2003). However snack foods can be high in fat and energy dense and perhaps nurses need advice on making suitable snack choices as well as ensuring they have access to healthy food. Eating healthily whilst in a food rich environment where unhealthy choices are readily available can be difficult for nurses who work any shift (Allom \& Mullan, 2008) but this can be even more challenging at night when access to healthy food can be more restricted. It is also likely that shift working nurses may have fewer opportunities to eat with friends and family (Morikawa et al., 2008) and eating together can be of benefit to the whole family (Boutelle et al., 2003). Food is an important circadian synchroniser, and even where there are not changes in total amounts consumed, the timing of the food intake and meals can change in relation to the shifts that are worked. Nibbling and snacking are common amongst shift workers (Costa, 2010) furthermore current research has shown that the timing of food intake is linked to body weight and metabolic health (Garaulet \& Gómez-Abellán, 2014). The timing and distribution of food intakes was beyond the scope of this study but warrants further attention since this could directly affect metabolic efficiency (Garaulet et al., 2013)

The findings of this study could be strengthened with greater recruitment of male nurses and night shift workers, however in order to ensure this recruitment would need to include other healthcare facilities in Malta. This study was based on self-reported data and FFQs. Whilst we need to consider the possibility of under-reporting there are studies that indicate that semiquantitative FFQs can provide reasonably valid and reproducible data (McKeown et al., 2001; Rimm et al., 1991). A further limitation of the study was that no blood biochemistry measurements were taken. A recent study of police officers showed that shift work was not significantly associated with lipid profiles, however amongst female officers there were 
correlations between triglycerides and total cholesterol and poor sleep quality (Charles, 2015), a common symptom of shift work that many night workers suffer (Huth et al., 2013).

This study has shown differences in the dietary intake of rotating and night shift nurses compared to day nurses and in the long term this may influence the risk of becoming overweight or obese. Nurses can be considered at high risk of being overweight or obese not only because of their diet, but physical activity and stress (Adeb-Saeedi, 2002) but also due to the overriding effect of working shifts.

The experiences of nurses with regards to diet and lifestyle should be taken into consideration and used to encourage improved health behaviours. Nurses and particularly A \& E nurses may encounter many physical and mental pressures during the course of their work and this coupled with circadian disruption caused by shift work can constitute a potential health hazard. All wards in the hospital where the study was conducted are equipped with basic catering appliances so it is possible for nurses to prepare/cook healthy snacks and meals at home and bring to work. Furthermore the hospital canteen should provide a selection of healthy food. Small and frequent meals embraced with suitable timing of healthy eating should be part of the daily routine in all nurses to avoid health problems in relation to circadian interference. This should be part of the health education included in the foundation knowledge within the nursing curriculum. The nutritional status of nurses could be monitored periodically and could be used as a screening tool by qualified health personnel to reduce occupational health risks while improving employee health and performance.

\section{Conclusion}

http://mc.manuscriptcentral.com/nfs 
These findings provide additional information to show that shift work can influence the diet of nurses in Malta. Since Malta has one of the highest levels of obesity in Europe (Ng et al., 2014; World Health Organisation, 2015) it is important to understand some of the many factors that influence weight gain and obesity, including the role of occupational hazards such as shiftwork. Recommendations for hospitals include ensuring healthy food is available and time and facilities for physical activity exist. Recommendations for all nurses including those that work shifts is to ensure they consume healthy meals, snacks and beverages and that they aim to exercise regularly, quit smoking and get adequate amounts of sleep where possible.

\section{Acknowledgements}

This work was supported through the MASTER it Scholarship Scheme as part of the Operational Programme II - Cohesion Policy 2007-2013, co-financed by the European Social Fund and the Government of Malta. The authors would like to acknowledge the contribution of the staff and participants of the original EPIC-Norfolk study for use of the FFQ and all the nurses that participated in this study.

\section{References}

Adeb-Saeedi, J. (2002), "Stress amongst emergency nurses”, Australian Emergency Nursing Journal, Vol. 5, No. 2, pp.19-24.

Allom, V. and Mullan, B. (2014),"Maintaining healthy eating behaviour: experiences and perceptions of young adults", Nutrition \& Food Science, Vol. 44 No. 2, pp. 156 - 167

Atkinson, G., Fullick, S., Grindey, C., Maclaren, D. and Waterhouse, J. (2008), "Exercise, energy balance and the shiftworker", Sports Medicine,Vol. 38 No. 8, pp. 671-685. 
Boutelle, K., Birnbaum, A., Lytle, L., Murray, D. and Story, M. (2003). “Associations between perceived family meal environment and parent intake of fruit, vegetables and fat", Journal of Nutrition Education and Behavior, Vol. 35, No.1, pp. 24-29.

Chennaoui, M., Arnal, P.J., Sauvet, F. and Léger, D. (2015), “Sleep and exercise: a reciprocal issues? Sleep Medicine Reviews, Vol. 2 No. 4 pp. 59-72.

Charles, L.E., Gu, J.K., Tinney-Zara, C.A., Fekedulegn, D., Ma, C.C., Baughman, P., Hartley, T.A., Andrew, M.E., Violanti, J.M. and Burchfield, C.M. (2016), "Separate and joint associations of shiftwork and sleep quality with lipids", Safety and Health at Work, doi: 10.1016/j.shaw.2015.11.007.

Chin, D.L., Nam, S. and Lee, S.J. (2016), “Occupational factors associated with obesity and leisure-time physical activity among nurses: A cross sectional study”, International Journal of Nursing Studies in press, http://dx.doi.org/doi:10.1016/j.ijnurstu.2016.01.009

Costa, G. (2010), “Shift Work and Health: Current Problems and Preventive Actions”, Safety and Health at Work, Vol. 1, No. 2 pp. 112-123.

Dallman, M.F., Pecoraro, N., Akana, S.F., La Fleur, S.E., Gomez, F., Houshyar, H., Bell, M.E., Bhatnagar, S., Laugero, K.D. \& Manalo, S. (2003), “Chronic stress and obesity: a new view of 'comfort food"' Proceeding of the National Academy of Sciences of the United States of America, Vol. 100 No. 20 pp. 11696-11701.

Dekkers, J.C., van Wier, M.F., Hendriksen, I.J., Twisk, J.W. and Mechelen, W. (2008), "Accuracy of self-reported body weight, height and waist circumference in a Dutch overweight working population”, BMC Medical Research Methodology, Vol. 28 No. 8, pp. 69. 
Dorrian, J., Heath, G., Sargent, C., Banks, S. and Coates, A. (2015), “ Alcohol use in shiftworkers", Accident Analysis and Prevention, http://dx.doi.org/10.1016/j.aap.2015.11.011

Driesen, K., Jansen, N.W.H., Kant, I., Mohren, D.C.L. and van Amelsvoort, L.G.P.M. (2010), “ Depressed mood in the working population: associations with work schedules and working hours", Chronobiology International, Vol. 27, No. 5 pp. 1062-1079.

Erlacjer, C., Erlacher, D. and Schredl, M. (2015), “The effects of exercise of self-rated sleep among adults with chronic sleep complaints", Journal of Sport and Health Science, Vol. 4, No. 3 pp. $289-298$.

Eurofound (2005) "Fourth Working Conditions Survey”, http://www.eurofound.europa.eu/ewco/surveys/ewcs2005/index. Accessed 18.12.15

Eurofound (2015) "Sixth European Working Conditions survey”, http://www.eurofound.europa.eu/publications/resume/2015/working-conditions/firstfindings-sixth-european-working-conditions-survey-resume. Accessed 18.12.15

European Prospective Investigation of Cancer (2014) http://www.epic-norfolk.org.uk/ Accessed 1.12.14.

Formosa, G. (2009) "Working time in the European Union; Malta", http://www.eurofound.europa.eu/observatories/eurwork/comparative-information/nationalcontributions/malta/working-time-in-the-european-union-malta Accessed 18.12.15.

Garaulet, M., Gomez-Abellan. P., Alburgerque-Bejar. J.J., Lee, Y.C., Orddovas, J.M. and Scheer, F.A.J.L. (2013) “Timing of food intake predicts weight loss effectiveness”, International Journal of Obesity, Vol 37 pp. 604-611.

Garaulet, M. and Gómez-Abellán, P. (2014), “Timing of food intake and obesity: a novel association", Physiology Behavior, Vol. 134 pp. 44-50. 
Griep, R.H., Bastos, L.S., Silva-Costa, A., Fonseca, M.J., Portela, L.F., Toivanen, S. and Rotenberg, L. (2014), "Years worked at night and body mass index among registered nurses from eighteen public hospitals in Rio de Janeiro, Brazil”, BMC Health Services Research, Vol. 14, pp. 603.

Huth, J.J., Eliades, A., Handwork, C., Englehart, J.L. and Messenger, J. (2013), “Shift worked, quality of sleep and elevated body mass index in pediatric nurses", Journal of Pediatric Nursing Vol. 28 pp. e64-73.

Karlsson, B., Knutsson, A., and Lindahl B. (2001), "Is there an association between shift work and having a metabolic syndrome? Results from a population based study of 27,485 people," Occupational and Environmental Medicine, Vol. 58, No. 11, pp. 747-752.

Knutsson, A. and Bøggild, H. (2000), “Shiftwork and cardiovascular disease: review of disease mechanisms", Reviews on Environmental Health, Vol. 15 No. 4 pp. 59-372.

Kyle, R.G., Neall, R.A. and Atherton, I.M. (2016), "Prevalence of overweight and obesity among nurses in Scotland: A cross-sectional study using the Scottish Health Survey”, International Journal of Nursing Studies Vol. 53 pp. 126-133.

Lennernas, M., Hambraeus, L. and Akerstedt, T. (1994), "Nutrient intake in day and shift workers", Work \& Stress, Vol.8 pp. 332-342.

Li, S.Y. and Yamaguchi, N. (2011), "Shift work and the risk of metabolic syndrome: a nested case-control study", International Journal of Occupational and Environmental Health, Vol. 17, No. 2 pp. $154-60$.

Lieu, S.J., Curhan, G.C., Schernhammer, E.S. and Forman J.P. (2012), "Rotating night shift work and disparate hypertension risk in African-Americans," Journal of Hypertension, Vol. 30, No. 1, pp. 61-66, 2012. 
Lowden, A., Moreno, C., Holmbäck, U., Lennernäs, M. and Tucker P. (2010), “Eating and shift work effects on habits, metabolism, and performance", Scandinavian Journal of Work, Environment \& Health, Vol. 36, No. pp. 150-152.

Macagnan, J., Pattussi, M.P., Canuto, R., Henn, R.L., Fassa, A.G. and Olinto, M.T. (2012), "Impact of nightshift work on overweight and abdominal obesity among workers of a poultry processing plant in southern Brazil”, Chronobiology International, Vol. 29, No.3 pp. 336-43.

Marqueze E. C., Ulhôa M. A. and Moreno C. R. (2013), "Effects of irregular-shift work and physical activity on cardiovascular risk factors in truck drivers", Revista de Saude Publica, Vol. 47, No. 3 pp. 497-505.

McKeown, N.M, Welch, A.M., Runswick, S.A., Luben, R., Mulligan, A.,McTaggart, A., Day, N.E. and Bingham, S.A (2001), "The use of biological markers to validate self reported dietary intake in a random sample of the European Prospective Investigation into cancer (EPIC) UK Norfolk Cohort”, American Journal of Clinical Nutrition, Vol. 74, No. 2 pp. 188196.

Morikawa, Y., Miura, K., Sasaki, S., Yoneyama, S., Sakurai, M., Ishizaki, M., Kido, Naruse, Y., Suwazono, Y., Higashiyama, M. and Nakagawa, H. (2008), "Evaluation of the Effects of Shift Work on Nutrient Intake: A Cross-sectional Study" Journal of Occupational Health, Vol. 50, No. 3 pp. 270-278. 
Nojkov, B., Rubenstein, J.H., Chey, W.D. and Hoogerwef, W.A. (2010), “The Impact of Rotating Shift Work on the Prevalence of Irritable Bowel Syndrome in Nurses", American Journal of Gastroenterology, Vol. 105, No, 4 pp. 842-847.

Ng, M., Fleming, T., Robinson, M., Thomson, B., Graetz, N. et al. (2014), “Global, regional, and national prevalence of overweight and obesity in children and adults during 1980-2013: a systematic analysis for the Global Burden of Disease Study”, Lancet, Vol. 384 pp. 766-781.

Persson, M. and Martensson, J. (2006), "Situations influencing habits in diet and exercise amongst nurses working night shift", Journal of Nursing Management, Vol. 14 pp. 414-423.

Reeves, S.L., E. Newling-Ward and Gissane , C. (2004),"The effect of shift-work on food intake and eating habits", Nutrition \& Food Science, Vol. 34 No. 5 pp. 216 - 221

Rimm, E.B., Giovannucci, E.L., Stampfer M.J., Colditz G.A., Litin, L.B. and Willett, W.C. (1991), "Reproducibility and Validity of an Expanded Self-Administered Semi-quantitative Food Frequency Questionnaire among Male Health Professionals”, American Journal of Epidemiology, Vol. 135, No. 10 pp. 1114-1126.

World Health Organisation (2015), “The European health report 2015. Targets and beyond Reaching new frontiers in evidence", http://www.euro.who.int/en/data-andevidence/european-health-report/european-health-report-2015/european-health-report-2015the.-targets-and-beyond-reaching-new-frontiers-in-evidence.-highlights. Accessed 3.2.16.

Zhao, I., Bogossian, F., Song, S. and Turner, M.N. (2011), “The Association between shift work and unhealthy weight: A cross-sectional analysis from the nurses and midwives' ecohort study", Journal of Occupational and Environmental Medicine, Vol. 53, No. 2 pp. 153158.

Zimberg, I.Z., Fernandes Junior, S. A., Crispim, C. A., Tufik, S. and de Mello, M.T. (2012).

“The metabolic impact of shift work", Work, Vol. 41, No. S1 pp. 4376-4383. 
Table 1. Anthropometric measurements $($ mean \pm SD) of male and female nurses according to work pattern

\begin{tabular}{|l|r|c|l|l|c|}
\hline & $\mathrm{n}$ & Age (years) & $\begin{array}{l}\text { BMI } \\
\left(\mathrm{kg} / \mathrm{m}^{2}\right)\end{array}$ & $\begin{array}{l}\text { Waist } \\
\text { Circumference } \\
(\mathrm{cm})\end{array}$ & Waist hip ratio \\
\hline Day Nurses & & & & & \\
\hline Female & 20 & $34.5 \pm 10.0$ & $25.7 \pm 5.1$ & $80.2 \pm 11.8$ & $0.80 \pm 0.09$ \\
\hline Male & 9 & $38.7 \pm 15.2$ & $25.4 \pm 5.6$ & $87.3 \pm 13.2$ & $0.91 \pm 0.06$ \\
\hline $\begin{array}{l}\text { Rotating shift } \\
\text { nurses }\end{array}$ & & & & & \\
\hline Female & 49 & $26.7 \pm 5.0^{\mathrm{a}}$ & $26.0 \pm 5.2$ & $81.9 \pm 13.4$ & $0.80 \pm 0.08$ \\
\hline Male & 19 & $26.8 \pm 3.8^{\mathrm{b}}$ & $27.3 \pm 4.3$ & $94.6 \pm 12.5$ & $0.93 \pm 0.07$ \\
\hline Night shift nurses & & & & & \\
\hline Female & 10 & $41.7 \pm 11.5$ & $26.3 \pm 3.1$ & $91.7 \pm 13.5$ & $0.84 \pm 0.06$ \\
\hline Male & 3 & $35.3 \pm 5.0$ & $29.2 \pm 1.8$ & $92.2 \pm 12.4$ & $1.10 \pm 0.10^{\mathrm{c}}$ \\
\hline
\end{tabular}

Rotating shift nurses were significantly younger than day and night shift nurses; ${ }^{a}$ female nurses $(p=0.001),{ }^{b}$ male nurses $(p=0.007) .{ }^{c}$ Male night shift nurses had a significantly higher waist hip ratio compared to day and rotating shift nurses $(p=0.02)$ 


\section{Figure 1. Lifestyle habits of shift working nurses in Malta}

Chi-square tests revealed no significant differences between groups for alcohol consumption or physical activity. Day nurses were significantly more likely to smoke $(p=0.009) n=110$. 
Table 2. Nutrient intakes (mean \pm SD) of nurses according to gender and work pattern

\begin{tabular}{|c|c|c|c|}
\hline & Day Nurses & $\begin{array}{l}\text { Rotating Shift } \\
\text { Nurses }\end{array}$ & Night Shift Nurses \\
\hline \multicolumn{4}{|c|}{ a. Both genders } \\
\hline Energy (kcal) & $1722 \pm 486^{\mathrm{a}}$ & $2065 \pm 655$ & $1963 \pm 506$ \\
\hline Carbohydrate (g) & $186.4+56.9$ & $221.8+70.4$ & $210.4+64.9$ \\
\hline Total sugars $(\mathrm{g})$ & $102.5 \pm 40.6$ & $120.9 \pm 46.4$ & $115.5 \pm 49.6$ \\
\hline Fibre $(\mathrm{g})$ & $19.4+8.2^{\mathrm{d}}$ & $24.3 \pm 10.2^{\mathrm{d}}$ & $29.3 \pm 9.0^{\mathrm{d}}$ \\
\hline Fat $(\mathrm{g})$ & $66.2 \pm 21.7^{b}$ & $82.2+32.2$ & $77.1 \pm 26.7$ \\
\hline Protein $(\mathrm{g})$ & $95.4 \pm 29.9^{\mathrm{c}}$ & $113.3 \pm 24.1$ & $114.6 \pm 17.9$ \\
\hline Alcohol (g) & $6.4 \pm 8.8$ & $5.6 \pm 5.3$ & $2.8 \pm 3.3$ \\
\hline \multicolumn{4}{|c|}{ b. Female data only } \\
\hline Energy (kcal) & $1720 \pm 516$ & $2053 \pm 697$ & $1989 \pm 565$ \\
\hline Carbohydrate (g) & $191.0 \pm 57.7$ & $224.2 \pm 74.6$ & $216.8 \pm 69.4$ \\
\hline Total sugars $(\mathrm{g})$ & $105.9 \pm 38.0$ & $125.7 \pm 47.4$ & $121.0 \pm 55.1$ \\
\hline Fibre $(\mathrm{g})$ & $18.5 \pm 7.9^{\mathrm{e}}$ & $25.4 \pm 10.5$ & $31.4 \pm 7.6$ \\
\hline Fat $(\mathrm{g})$ & $67.9 \pm 24.0$ & $80.4 \pm 33.7$ & $78.1 \pm 29.8$ \\
\hline Protein $(\mathrm{g})$ & $91.3 \pm 32.5^{\mathrm{f}}$ & $112.6 \pm 36.0$ & $114.6 \pm 19.4$ \\
\hline Alcohol (g) & $3.7 \pm 4.2$ & $5.2 \pm 5.5$ & $1.8 \pm 2.4$ \\
\hline \multicolumn{4}{|c|}{ c. Male data only } \\
\hline Energy (kcal) & $1729 \pm 439$ & $2097 \pm 549$ & $1878 \pm 291$ \\
\hline Carbohydrate (g) & $176.0 \pm 57.1$ & $215.7 \pm 59.7$ & $189.1 \pm 52.4$ \\
\hline Total sugars $(\mathrm{g})$ & $94.9 \pm 47.4$ & $108.7 \pm 42.5$ & $97.2 \pm 20.2$ \\
\hline Fibre $(\mathrm{g})$ & $21.4 \pm 9.1$ & $21.4 \pm 8.8$ & $22.1 \pm 11.3$ \\
\hline Fat $(\mathrm{g})$ & $62.5 \pm 16.1$ & $86.7 \pm 28.1$ & $73.8 \pm 15.5$ \\
\hline Protein $(\mathrm{g})$ & $104.4 \pm 22.0$ & $115.1 \pm 29.6$ & $114.6 \pm 14.7$ \\
\hline Alcohol (g) & $12.4 \pm 13.1$ & $6.5 \pm 4.4$ & $6.3 \pm 4.2$ \\
\hline
\end{tabular}

${ }^{a}$ In the combined gender data there was a significant difference in the energy $(p=0.04),{ }^{b}$ fat $(p=0.047)$ and ${ }^{c}$ protein $(p=0.04)$ intakes between the day nurses and the shift working nurses. ${ }^{d}$ There were significant differences in fibre intake between all three groups $(p=0.005)$. The female only data showed significant differences between ${ }^{e}$ fibre $(p=0.002)$ and ${ }^{f}$ protein $(p=0.005)$ intakes for day nurses compared to shift working nurses. 